\title{
Papillon-Lefèvre syndrome: from then until now
}

\author{
Faiez N. Hattab \\ Department of Pediatrics, University Children's Hospital, Ulm D-89070 (joined), Germany. \\ Correspondence to: Dr. Faiez N. Hattab, Gerhard-Stötzel, Str. 8, Essen 45139, Germany. E-mail: f_hattab@hotmail.com \\ How to cite this article: Hattab FN. Papillon-Lefèvre syndrome: From then until now. Stomatological Dis Sci2019;3:1. \\ http://dx.doi.org/10.20517/2573-0002.2018.22
}

Received: 29 Aug 2018 First Decision: 17 Sep 2018 Revised: 13 Nov 2018 Accepted: 20 Dec 2018 Published: 16 Jan 2019

Science Editors: Nikolaos Nikitakis, Eduardo Fernandez, Evangelia Piperi Copy Editor: Cui Yu Production Editor: Huan-Liang Wu

\begin{abstract}
Papillon-Lefévre syndrome (PLS) is a very rare autosomal recessive trait characterized by palmoplantar hyperkeratosis and severe generalized early-onset periodontitis leading to premature loss of both primary and permanent dentitions. The etiopathogenesis of the disorder is multifactorial with genetic, immunological, and microbial factors playing a major role. Other significant factors involved are environmental and reduced host defense mechanism. Consanguinity is a contributing factor because of its relevance to clinical genetics. The genetic defect underlying etiology of PLS is mutations of the gene 11q14-q21encoding for cathepsin C, an enzyme involved in a variety of inflammatory and immune processes. Virulent pathogens and their toxins in the subgingival plaque play a major factor in the initiation and progression of PLS periodontitis. Dysfunction of leukocytes is secondary causative factor. Variable clinical expression, late onset of symptoms, and frequent gene mutations reflect the complexity of the syndrome. Today, over 300 cases been reported in dental and medical literature with more cases discovered among Arabs, Indians, and Africans. About 20\%-25\% of patients with PLS have increased susceptibility to infections besides overwhelming destructive periodontitis. Management of the disorder directed toward halting periodontal destruction by eliminating the reservoir of causative organisms; using conventional periodontal treatment, oral hygiene instructions, antiseptic mouth rinses; and systemic antibiotic. Skin lesions usually treated with topical application of emollients, keratolytic agents, steroids, and oral retinoid. Any attempt to achieve and preserve healthy oral conditions will improve quality of life in patients with this intriguing syndrome.
\end{abstract}

Keywords: Papillon-Lefévre syndrome, etiopathogenesis, consanguinity, diagnosis, management

\section{INTRODUCTION}

In 1924, the French physicians Papillon and Lefévre described a brother and sister; the products of first cousin matching, with condition characterized by palmoplantar hyperkeratosis (PPK) and severe early-onset periodontitis ${ }^{[1]}$. Gorlin et al. ${ }^{[2]}$ reviewed 46 Papillon-Lefévre syndrome (PLS) cases described in the literature. They added calcification of the falx cerberi to the syndrome, converting it into a triad. The prevalence of

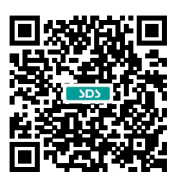


PLS in the general population was 1-4 cases per million. In review of 124 PLS cases, Haneke ${ }^{[3]}$ concluded that: (1) males and females were equally affected; (2) there was no racial predominance of the condition; (3) consanguinity is a feature in one-third of the cases; and (4) an increased susceptibility to infection, beside periodontitis, in $25 \%$ of PLS patients.

The criteria used for PLS diagnoses include presence of PPK, loss of primary and permanent teeth, and autosomal recessive inheritance ${ }^{[3]}$. The PLS disorder has since been discovered to be associated with two cardinal features: (1) aggressive periodontal disease associated with premature and extensive loss of teeth and alveolar bone in very young individual; and (2) PPK or keratoderma ${ }^{[1-5]}$.

Recent evidence indicated higher incidence of PLS among consanguineous families and in certain racial populations than previously reported. Review of literature revealed that $75 \%$ of the Arab probands were products of close parental consanguinity ${ }^{[6]}$. Increased occurrence of PLS became evident in Arabs ${ }^{[6-8]}$ and Indian populations ${ }^{[9-13]}$ as well as in isolated societies. In Jewish isolate family from Cochin, India (known as "Cochin Jews"), the frequency of the PLS gene was $0.1^{[14]}$. In Slovenia of 2 million inhabitants, Kansky et al. ${ }^{[15]}$ identified 13 PLS cases in seven distant families.

The early deterioration of oral and dermatological changes of children with PLS might instigate lifelong functional, aesthetical, psychological and social impacts on the growing children. Any attempt to achieve and preserve healthy oral conditions will improve quality of life for children with PLS. The aim of this article is to present review of the current literature regarding the etiopathogenesis, clinical features, laboratory investigation, differential diagnosis and management of this intriguing syndrome.

\section{PLS and hereditary}

PLS is a very rare autosomal recessive trait. In recessive genetic disorders, sibling inherits two copies of abnormal gene for the same trait, one from each parent. Typically, the parents are not affected and there is no family history of this disorder compared with affected persons. The carrier frequency of PLS was estimated at 2-4 per 1000 people $^{[5]}$. If both parents are carriers of the defective autosomal gene, there is a $25 \%$ risk for their children to be affected and 50\% to be carriers of the disease. Our studies on four Arab Jordanian and Qatari PLS families having 8 with classic PLS among 22 siblings, that is $36 \%$ of the siblings were affected. Parents were consanguineous, phonetypically healthy with no family history of the disease. The risk was the same for males and females ${ }^{[4,6]}$.

\section{PLS and consanguinity}

Consanguinity is deeply rooted social trend among one-fifth of the world population ${ }^{[16,17]}$. Many Arab countries display some of the highest rates (50\%) of consanguineous marriages in the world, and specifically first cousin marriages, which may reach $25 \%-30 \%$ of all marriages ${ }^{[17]}$. Data on Jordanians revealed that the rate of consanguineous marriages accounted for $51.3 \%$ with $33 \%$ first cousins marriage ${ }^{[18]}$. In Saudi Arabia, the rate of consanguineous marriages was $57.7 \%$ with first cousins (28.4\%), second cousin (14.6\%), and distant relative marriages $(15.2 \%)^{[19]}$. Similar rate also reported in Iraq and Arabian Gulf countries. In Egypt, the consanguineous marriages account for $35.3 \%$ with the majority among first cousins ${ }^{[2]}$. In Indian Mangalore communities, the frequency of consanguinity varies significantly between different religious groups. Hindus have the highest rate of consanguinity, which stood at $47.6 \%$, among which $43.4 \%$ were the first-cousin marriages ${ }^{[21]}$. The rate of consanguinity among Cochin Jews was $40 \%{ }^{[5]}$. In a literature review, Hattab and $\operatorname{Amin}^{[6]}$ reported that one-third of the total worldwide PLS cases were Arabs (80 of 250 cases) with $75 \%$ of the 80 cases having a history of parental consanguineous.

Multifactorial disorders are caused by genetic, environmental, and the interaction of genetic and environmental factors. A study on Egyptian patients who attended the Genetics clinic showed that recessive 
and multifactorial disorders had the highest values of consanguinity ( $78.8 \%$ and $69.8 \%$, respectively) and that the offspring of consanguineous unions are at increased risk for genetic disorders ${ }^{[20]}$.

\section{PLS occurrence}

A review of the literature up to year 1995 revealing about 200 cases of PLS has been published. Of those cases 35\% appeared during the period of 1980 and $1995^{[4]}$. The number of cases until 2005 was about 250; with most cases reported by dentists ${ }^{[6]}$. Literature revealed that over half of the worldwide PLS cases has been reported during the past three decades. Baghdady ${ }^{[22]}$ (1982) reported the first Arab-Iraqi patients with PLS in four from in two families. Pareek and Al-Aska ${ }^{[23]}$ (1986) described the first PLS in six Saudi children of the same family. El Darouti et al. ${ }^{[24]}$ (1988) identified and treated 3 Egyptian patients with PLS. Hattab et al. ${ }^{[4]}$ (1995) described the first PLS cases of Arab-Jordanian, where 4 siblings from two consanguineous families were affected. Yacoub and Hattab ${ }^{[25]}$ (2008) identified the first PLS in two siblings from Qatari family. Soyele and Taiwo ${ }^{[26]}$ (2015) reported the first case of PLS in Nigeria. In 2017, PLS cases in Yemenis were diagnosed ${ }^{[27]}$. Series of PLS probands has been reported. Ghaffer et al. ${ }^{[2]}$ (1999) diagnosed 15 PLS cases from 4 families in Egypt. AIBarrak et al. ${ }^{[7]}$ (2016) identified five cases of PLS in the same Saudi family. Valeshabad et al. ${ }^{[29]}$ (2012) found six PLS cases in the same Iranian family. Three PLS cases in the same Yemeni family ${ }^{[27]}$ and in Turkish family ${ }^{[30]}$ have been reported. Two cases of PLS in the same Indian families were detected ${ }^{[10,31]}$. Most of affected siblings were products of consanguineous healthy parents. Today, over 300 cases have been reported in dental and medical literature.

\section{ETIOLOGY}

The etiology of PLS is multifactorial, with genetic, immunological, and microbial being the main causal factors. Other significant factors are environmental and compromised host defense mechanisms owing to the decreased function of lymphocytes, polymorphonuclear leukocytes (PMNs), or monocytes. A genetic predisposition with greater frequency of occurrence in consanguineous offspring has been reported ${ }^{[4,5]}$.

\section{Genetical aspect}

Laass et al. ${ }^{[32]}$ (1997) were the first that mapped the PLS locus on chromosome 11q14-q21. In 1999, two independent research groups identified mutations of the gene linked to PLS. These gene mutations found to be associated with loss function of cathepsin C enzyme; known as dipeptidyl peptidase $1^{[33,34]}$.

Cathepsin C (CTSC) is lysosomal cysteine protease involves in wide variety of immune and inflammatory responses by activating serine proteinases; an enzyme implicated in activation of phagocytic cells and T-lymphocytes, activating of various inflammatory mediators and specific receptors, and modulating the levels of cytokines. High levels of CTSC gene expression were found in various immune cells and osteoclasts ${ }^{[35]}$. Rao et al.$^{[36]}$ (1997) suggested that CTSC gene is normally expressed in those epithelial regions and frequently affected by PLS such as the keratinized gingiva, palms, soles, and knees epidermis. Hewitt et al ${ }^{[37]}$ suggested that a complete loss-of-function of CTSC is necessary for the manifestation of the aggressive periodontitis phenotype. Mutations of this gene also result in two other closely related conditions, the HaimMunk syndrome (HMS) ${ }^{[38]}$ and aggressive prepubertal periodontitis ${ }^{[37,39]}$.

HMS caused by germline mutations in the lysosomal protease CTSC gene mapped to chromosome 11q14.1-q14.3. HMS affected subjects were found to be homozygous for the mutated CTSC allele. Parents were found heterozygous carriers. A common clinical manifestation of PLS, HMS, and prepubertal periodontitis is severe early-onset periodontitis. Thus, the three disorders seem to be caused by allelic mutations of the same gene (allelic variants) ${ }^{[5,38]}$. Although both PLS and HMS share the cardinal features of PPK and severe periodontitis, there are differences between their phenotypes including arachnodactyly (slender fingers and toes), acro-osteolysis (loss of bone tissue in the fingers and toes), hypertrophy of the fingernails and toe nails (onychogryposis), and a radiographic deformity of the phalanges of the hand. 


\section{Gene mutations}

Several mutations and polymorphisms have been reported in the CTSC gene in PLS probands from diverse ethnic groups. Toomes et al. ${ }^{[33]}$ (1999) defined the genomic structure of CTSC and found mutations in the eight families tested. Hart et al. ${ }^{[39]}$ (2000) listed 25 CTSC gene mutations from 32 PLS families. Lefèvre et al. ${ }^{[40]}$ (2001) reported eight new mutations in PLS families from Europe and North Africa. From 1999 until 2003,41 different mutations of the CTSC gene have been identified in PLS patients. Hewitt et al. ${ }^{[37]}$ (2004a) identified 21 CTSC gene mutations in Egyptian and Jordanian PLS families. Noack et al. ${ }^{[41]}$ (2004) found 12 different CTSC mutations in 10 PLS patients. In a comprehensive database search, Nagy et al. ${ }^{[42]}$ (2014) reported the occurrence of 75 mutations for the CTSC gene, in which 68\% of the mutations were homozygous in PLS patients. In very rare occasions, concurrence of PLS and other disorders have been reported. Hattab and Amin $^{[6]}$ (2005) added to the literature the first report on the co-occurrence PLS and type 1 oculocutaneous albinism in two Jordanian brothers. Analysis of these two rare recessive genetic conditions showed that both genes shared their chromosomal location (11q14.2-14.3), but not their pathogenic mechanism ${ }^{[43]}$.

\section{Immunological aspect}

A range of functional neutrophil defects in PLS, arising secondary to the CTSC has been demonstrated ${ }^{[44,45]}$. In addition to genetic alterations, several immunological, environmental and host factors are involved in the PLS periodontitis including: (1) reduced host response against virulent oral pathogens in periodontium ${ }^{[46-49]}$; (2) impaired neuropfils and monocytes chemotaxis, migration, and phagocytic function ${ }^{[46,50,51]}$. Defect in leukocyte adhesion ${ }^{[52]}$ and leukocytelysis ${ }^{[45]}$; (3) decreased mitogenic activity, reduced lymphocyte proliferative and reactivity ${ }^{[53-55]}$; (4) impaired Fc-receptor function, reversed ratio of T-helper to T-killer cells $^{[55-57]} ;(5)$ depressed cytotoxicity of natural killer cells ${ }^{[56,57]} ;(6)$ impaired production of superoxide radicals by $\mathrm{PMNs}^{[58,59]}$. Low peroxidase level in whole saliva ${ }^{[60]}$; $(7)$ elevation of serum and salivary $\operatorname{IgG}^{[61-63]}$ and plasma cytokines ${ }^{[45]}$; and (8) disruption of fibroblast and cementoblast function associated with defective periodontal ligament attachment ${ }^{[64]}$, imbalanced gingival collagenolytic activity ${ }^{[65,66]}$ and the presence of massive degenerated plasma cells in periodontal tissue ${ }^{[67,68]}$.

\section{Microbial aspect}

About 600-700 species colonize in dental plaque (bacterial biofilm) and the subgingival sites. The World Workshop in Periodontology (1996) has designated Actinobacillus actinomycetemcomitans (A.a), Porphyromonas gingivalis, Tannerella forsythia, T. denticolaas periodontal pathogens ${ }^{[69]}$. Of the microflora characterized in aggressive periodontitis, approximately 65\%-75\% of bacteria are Gram-negative anaerobes and facultative anaerobe bacilli, with few spirochetes or motile rods present ${ }^{[70-72]}$.

Microscopic examination and cultural studies of subgingival dental plaque in one or two PLS patients showed that the predominant periodontal pathogen was A.a, associated with elevated of salivary and serum IgG antibody levels ${ }^{[46,62,63]}$. High frequency of Gram-negative anaerobic rods including Porphyromonas gingivalis, Prevotella intermedia, Prevotella loescheii, Bacteroides gracilis was also identified ${ }^{[48,62,73]}$. Robertson et al. ${ }^{[73]}$ found that most isolates from two PLS patients were Capnocytophaga spp. and Streptococcus spp. Albandar et al. ${ }^{[74]}$ examined subgingival plaque from 13 PLS patients. They found of the total 170 bacterial species, a high frequency of A.a, Campylobacter spp., Capnocytophaga granulosa, Streptococcus spp., and Tannerella forsythia. Lundgren ${ }^{[60]}$ obtained samples from 36 sites in 12 Saudi PLS patients. He found that A.a and Porphyromonas gingivalis were infrequently encountered in high levels. High frequencies of viruses were identified in the active periodontal lesions ${ }^{[49,75]}$. Because of the diversity and complex subgingival microbial communities, no particular periopathogens invariably associated with PLS have been determined. However, the raised serum IgG antibody titers against A.a in PLS patients and that a successful treatment of periodontitis correlates with eradication of $A \cdot a^{[62,63,69,76-78]}$, which indicates that $A . a$ plays a significant role in the initiation and progression of periodontitis seen in PLS. 


\section{PATHOGENESIS}

Although the genetics behind the PLS disorder has been identified, the exact biological mechanism causing the dermatological or periodontal lesions is still unknown and the link between the cutaneous and gingival findings is unclear. Studies indicated that CTSC is essential for maintaining the structural organization of the epidermis of the extremities and the integrity of the tissues surrounding the teeth ${ }^{[79]}$. In immunity system, the helper $\mathrm{T}$ cells are the most important cells in adaptive immunity. They are involved in activating B-lymphocytes to secrete antibodies that engulf antigens and release cytokines to activate cytotoxic T lymphocyte (T killer cells) to kill infected target cells. The Fc-receptor is the antibody located at the membrane of certain immune cells involved in antigen recognition. Beside the periodontitis component of PLS, increased susceptibility to infections such as mild skin pyoderma, recurrent tonsillitis, respiratory tract infections, and pneumonia have been reported ${ }^{[3-5]}$. Recently, pyogenic liver abscess is recognized as a complication of PLS ${ }^{[80,81]}$. Several studies have reported late-onset and atypical variation of PLS ${ }^{[82-85]}$.

Periodontitis is a multifactorial phenomenon characterized by the presence of a variety of molecular species, among which are free radicals and reactive oxygen species (ROS). ROS are essential in a number of metabolic pathways but their excessive production can result in cell damage, as during the "respiratory burst" of phagocytosing leukocytes. When ROS overwhelm the cellular antioxidant defense system, whether through an increase in ROS levels or a decrease in the cellular antioxidant capacity, oxidative stress (elevated lipidhydroperoxide levels) occurs ${ }^{[86,87]}$. Neutrophils represent the first line of defense against microbial pathogens. Periodontitis in PLS arise from failure to eliminate periodontal pathogens. The lack of CTSC gene activity leads to deficient in neutrophil serine protease resulted in a reduced ability of neutrophil to chemotax efficiently and an inability to generate neutrophil extracellular traps. This could possibly explain the severe periodontitis in PLS ${ }^{[88,89]}$. Hyperactive neutrophil released higher levels of pro-inflammatory cytokines and reduced antimicrobial capacity. It also contributes significantly to the oxidative stress and antioxidant compromise. It is noteworthy that systemic immunodeficiency in PLS is relatively mild, with about $20 \%$ predisposed to recurrent infections, yet the local periodontitis is profoundly aggressive.

Based on the current findings it emerges, that dysfunction of PMNs is secondary to aggressive bacterial infection; influenced by the underlying loss of CTSC function and deficiency in host defense mechanism. The presence of virulent bacterial and viral infection in periodontium and the production of noxious enzymes and toxins like leukotoxins, collagenase, proteases, endotoxin, and epitheliotoxin indicate that PLS mediated bacteriologically.

\section{CLINICAL FEATURES}

\section{Oral manifestations}

The development and eruption of the primary and permanent teeth proceed normally. They erupt in normal sequences at the expected age or even earlier. Usually, the teeth are of normal forms and structures, cariesfree with no sign of root resorption ${ }^{[4,6,7]}$. The pathognomic oral features of typical PLS are as follows. Once the primary and permanent teeth erupted, the gingiva around the teeth becomes red, severely inflamed, swollen, tender, and bleeds easily [Figure 1]. This was followed by the formation of deep pathological periodontal pockets which exudates pus on slightest pressure. Dense plaque accumulation, multiple gingival abscesses, purulent exudates, teeth mobility, drifting, migration, and severe alveolar bone resorption with about 10 to $15 \%$ bone remaining around the teeth present are characteristics [Figures 1-3]. Brushing the teeth is difficult due to bleeding and sore gingiva on touch. Chewing is painful because of the mobility of teeth. Offensive oral malodor is usually present. Tenderness of the regional lymphadenopathy is a common finding. The rapidly progressing periodontitis is usually unresponsive to traditional periodontal treatment modalities. At the age of 4-5 years, the primary teeth become exfoliated or extracted and the child becomes completely edentulous. 


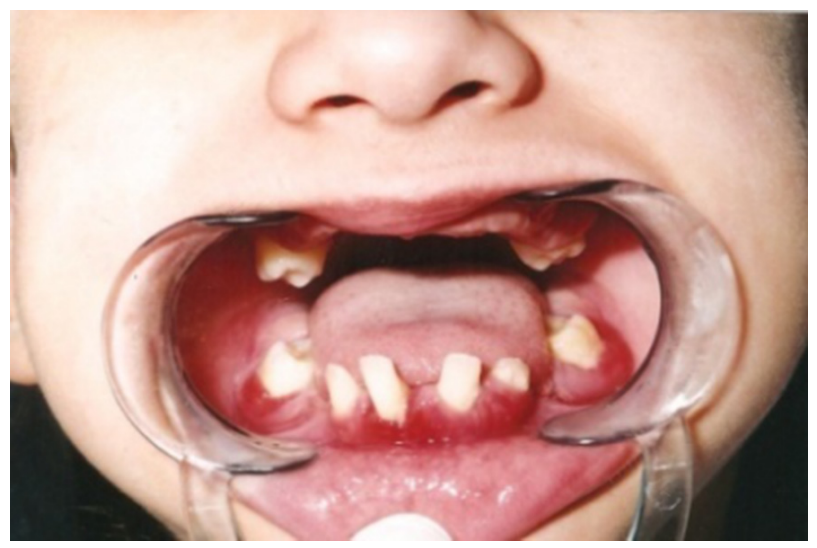

Figure 1. Nine-year old girl shows premature loss of the primary teeth. The gingival tissues around the newly erupted permanent teeth are red, swollen and severely inflamed ${ }^{[25]}$

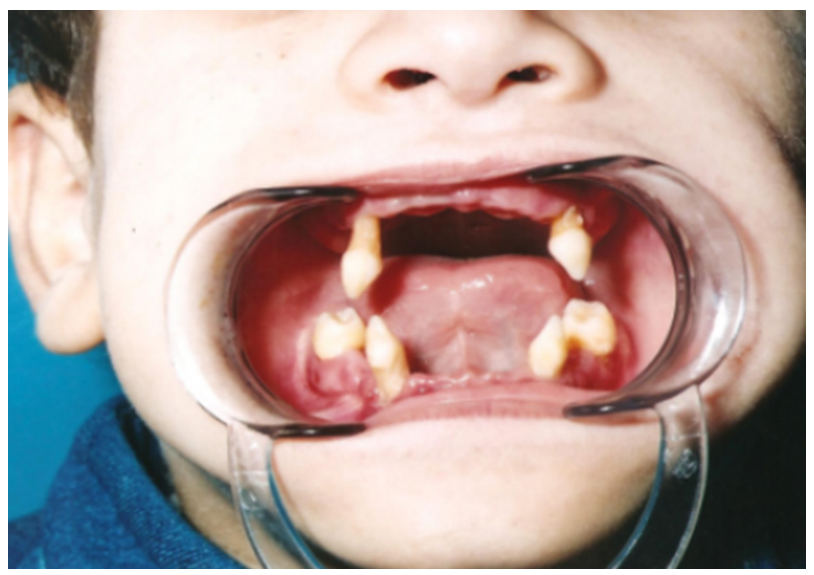

Figure 2. Five-year old boy reveal exfoliated teeth and the remaining primary teeth were mobile and extruded. The gingiva around the teeth is inflamed, hemorrhagic with alveolar bone lost ${ }^{[25]}$

Subsequently, the inflammation subsides and the gingiva return to its normal healthy state and mucosa covering the edentulous area appears normal. After the eruption of the permanent teeth, the same cycle of events begins; by age of about 15, almost all teeth are lost associated with atrophy of the alveolar ridge [Figure 3]. Later on, the third molar will erupted with uncertain fate. Clinical picture and panoramic radiograph show generalized loss of alveolar bone up to the apical third of the roots [Figures 2 and 3] giving the teeth a radiographic appearance of "floating in air ${ }^{\left[{ }^{[4]}\right.}$. The lateral view of the skull radiograph may depict ectopic intracranial calcification of the falx cerebral or tentorium [Figure 4].

\section{Dermatological manifestations}

The onset PPK may appear early at birth or 1-2 months of age, but most commonly between the ages of 6 months to 4 years, coinciding with eruption of the primary teeth associated with intensive gingivitis. Symptoms of PPK lesions exacerbate with increased severity of periodontitis ${ }^{[4,12,25,90]}$. Ullbro et al ${ }^{[91]}$ however, found no association between the degree of PPK and severity of periodontitis, and suggested that these two major components of PLS are unrelated to each other. Cutaneous lesions develop in pressure areas, such as palms, soles, knuckles, ankles, elbows and knees. The soles (planters) of feet were more severely affected than palms of the hands. Erythema always precedes hyperkeratosis. The skin lesions vary in color, texture, and manifestation. They may appear white or light yellow, brown or red. They presented as well-demarcated or diffused hyperkeratotic, erythematous, dry, rough, thick, scaly, fissured or cracked plaques and patches, 


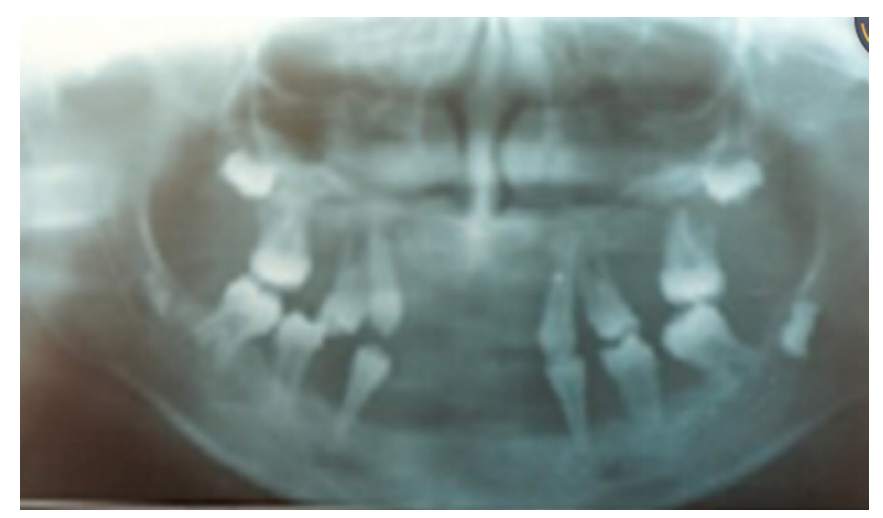

Figure 3. Panoramic radiograph of 10-year girl showing generalized severe alveolar bone loss with no evidence of root resorption, note the migration and floating of the lower first molar ${ }^{[4]}$

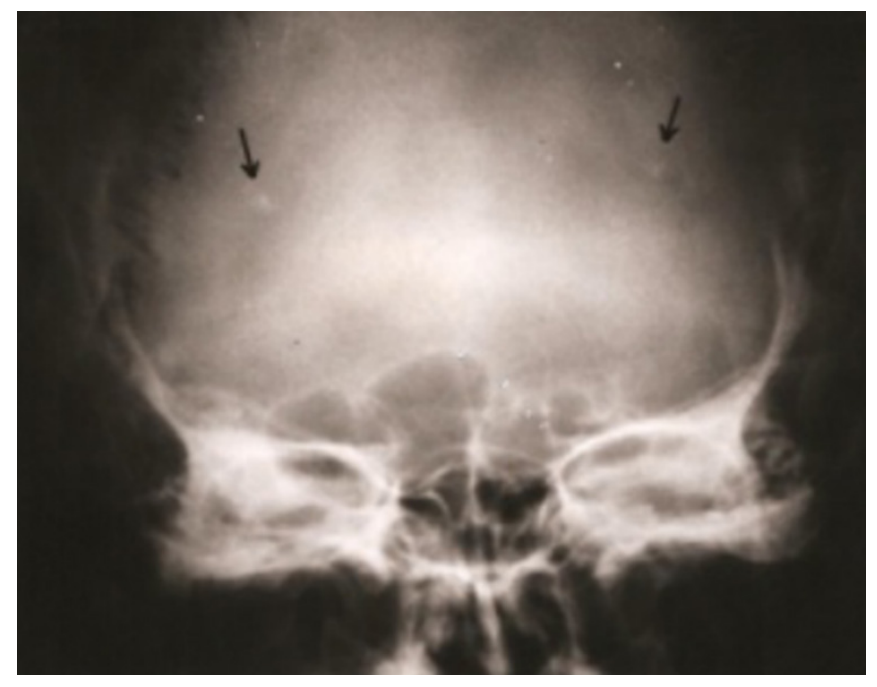

Figure 4. Skull radiograph show ectopic calcifications of the dura (arrows) ${ }^{[6]}$

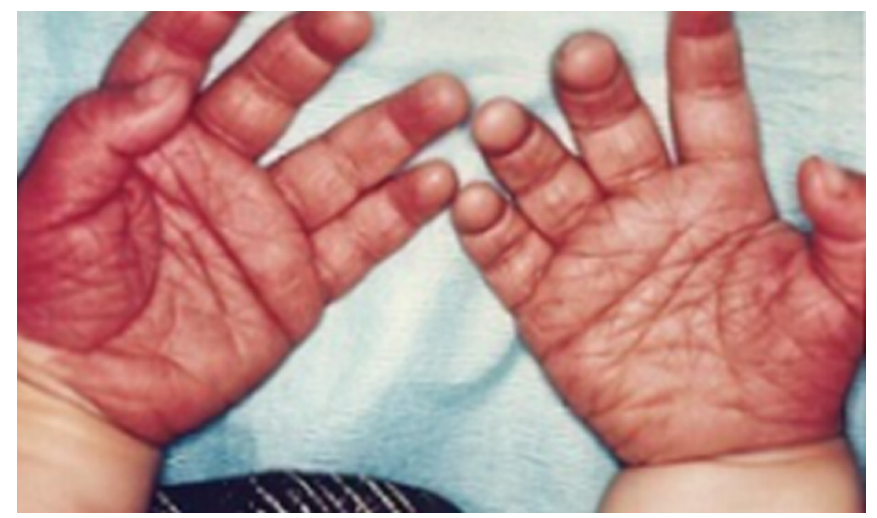

Figure 5. The palms of this four-year old girl show severe erythematous and deep grooves and ridges of the skin (unpublished image)

which involve the entire surfaces of the palms [Figures 5 and 6] and soles [Figure 7]. Thickened skin may peel off leaving a red, itchy area underneath. Lesions may spillover (transgrediens spread) to the dorsal surface of the hands particularly to eminences of the palms and to the ankles of feet, involving the Achilles tendon and external malleoli sites [Figure 8]. 


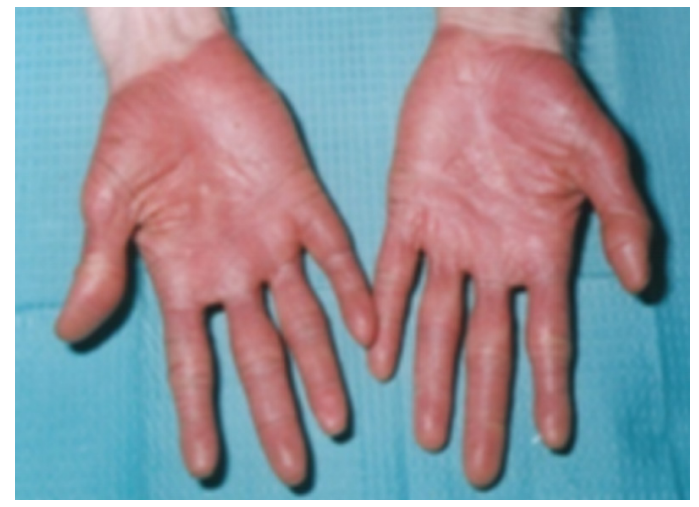

Figure 6. Well-demarcated hyperkeratosis, erythematous, scaly and cracked skin lesions of the palms; gives red glove-like appearance ${ }^{[6]}$

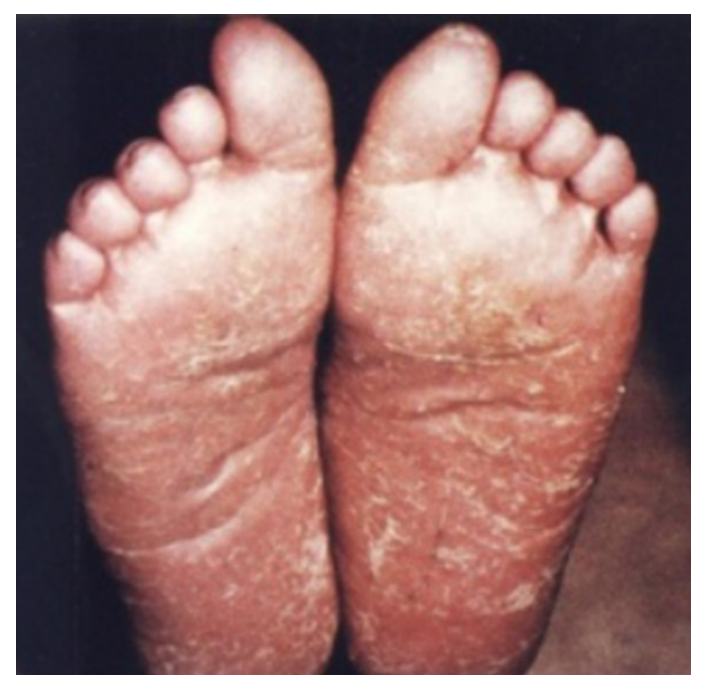

Figure 7. Soles of the feet shows diffused hyperkeratosis involving the entire plantar surface. The skin appears dry, rough, flaky, cracked with crustations (unpublished image)

Other sites of involvement include the knees [Figure 9] and elbows but less severe than the palmoplantar surfaces. Less frequently, lesions may be seen on the toes, legs, thighs, and rarely on the trunk. In some cases, the upper portions of the hands and feet, the eyelids, the lips, the cheeks, and/or other areas of the body may also be affected ${ }^{[4]}$. The skin lesions are aggravated during the cold winter period and are in remission in summer. They undergo crustations, cracking, and deep fissuring, making walking painful. Infection may superimpose the defective skin resulting in the formation of recurrent abscesses (pyoderma). Some patients may exhibit infection of hair follicles (furunculosis), multiple abscesses of the skin, malodorous excessive sweating (hyperhidrosis), follicular hyperkeratosis, and nail dystrophy. Clinical features showed no gender predominance in the occurrence and severity of the condition.

\section{Laboratory tests}

\section{Saliva test}

In a study on 16 children and young adults (aged 6-27 years) with PLS, Lundgren ${ }^{[60]}$ found that the saliva secretion rates and buffer capacity were significantly lower among the PLS patients compared with the controls.

\section{Hematological investigation}

Complete blood count, creatinine, uric acid, glucose, cholesterol, triglycerides, electrolytes, total protein, and phosphatase were within the normal range ${ }^{[4,6]}$. Liver profile, renal profile, and ultrasound of the abdomen 


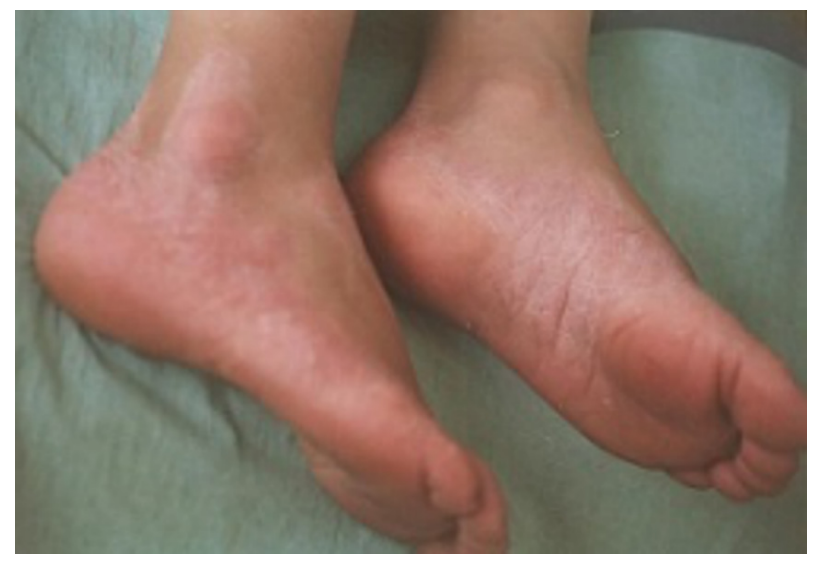

Figure 8. Planter surface keratotic lesions extended to the sides of the feet, involving Achilles tendon and external malleoli sites ${ }^{[4]}$

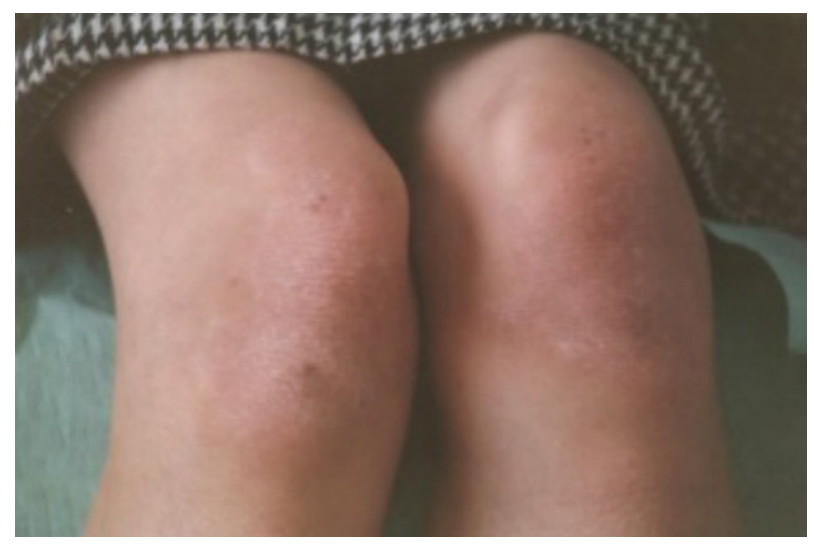

Figure 9. Well-circumscribed, erythematous, scaly, keratotic plaques on the knees ${ }^{[4]}$

and pelvis were normal ${ }^{[90]}$. Other specific blood analysis of immunoglobulin's $\operatorname{IgA}$, IgG and $\operatorname{IgM}^{[92]}$ and lymphocyte antigen receptors was within normal values ${ }^{[92,93]}$.

\section{Histopathological examination}

Skin biopsy from the PLS lesions showed thick layer of hyperkeratosis, focal parahyperkeratosis, hypergranulosis, acanthosis, and irregular rete pegs of the epidermis. Papillary dermis revealed vessel proliferation, perivascular mononuclear cells (lymphocytes and monocytes) infiltrate [Figure 10]. Gingival biopsy showed parakeratosis, acanthosis, and predominance of chronic inflammatory cells ${ }^{[4]}$.

\section{DIAGNOSTIC METHODS}

In general, children with PLS are moderately built and their physical and intellectual development levels are within normal limits. The first step in diagnosis of PLS is family and medical history. A pedigree reveals the mode of inheritance. Clinical oral and skin features as well as radiographic changes are pathognomic of PLS [Figures 1-10]. Biochemical analysis discloses alteration in the chemotaxis and phagocytic function of PMNs, particularly neutrophil. Diagnosis can make by urine analysis for CTSC activity of the suspected child soon after birth ${ }^{[94]}$. Reduced or no activity of CTSC enzyme is diagnostic of the disorder. Molecular genetic testing can detect alterations in the CTSC gene (11q14-21) and can thus confirm diagnosis, but this needs specialized laboratories. 


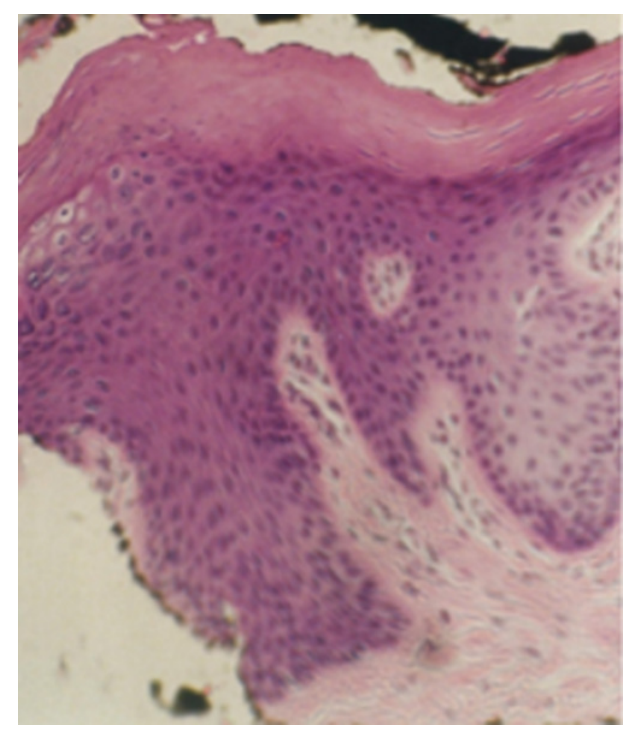

Figure 10. Skin lesion reveals hyperkeratosis, focal parakeratosis, hypergranulosis, acanthosis of epidermis and perivascular mononuclear cells infiltrate in papillary dermis ${ }^{[6]}$

\section{DIFFERENTIAL DIAGNOSIS}

Differential diagnosis includes disorders that are allelic variants of PLS, HMS and prepubertal aggressive periodontitis. PLS should differentiate from other conditions showing similar oral or cutaneous clinical features. Diseases with oral features similar to PLS periodontitis and premature loss of teeth are manifested in acrodynia, hypophosphatasia, severe congenital neutropenia, histiocytosis X, cyclic neutropenia, and Takahara syndrome. Other conditions with similar dermatologic features of PLS but not associated with periodontopathy are Unna Thost syndrome, Mal de Meleda, Howel-Evans syndrome, epidermolytic palmoplantar keratoderma (Vörner's syndrome), keratoderma hereditarium mutilans (Vohwinkel's syndrome), and Greither's syndrome ${ }^{[4,95]}$. These dermatological syndromes are inherited in an autosomal dominant pattern except Mal de Meleda, which is autosomal recessive.

\section{TREATMENT METHODS}

Efforts to treat PLS are traditionally directed by halting the rapid devastating periodontal destruction and reducing the hyperkeratotic skin lesions. This requires a multidisciplinary approach with family and child cooperation. Early periodontitis treatment and compliance with prevention program are the major determinants for preserving permanent teeth in young patients.

\section{Periodontal treatment}

The aim of periodontal treatment of the periodontal component of PLS is to eliminate the reservoir of periodontal pathogens and to create safe environment for eruption of permanent teeth. The treatment modalities include oral hygiene instruction, antibacterial mouthrinse, scaling and root planing, and systemic antibiotics. Reports of effectiveness of the treatment vary considerably. Tinanoff et al.$^{[48]}$ reported that administration of tetracycline $(250 \mathrm{mg} / \mathrm{t}$.i.d for one month) was unsuccessful in halting periodontitis. Preus and Gjermo $^{[47]}$ reported successful treatment of periodontitis over a four and a half year follow-up in two siblings receiving tetracycline intermittently $2-4$ weeks in periods of exacerbation and continuously during the last two years of the study. Hattab et al. ${ }^{[4]}$ used tetracycline for one week every month. Five months later, the gingiva around erupting and erupted teeth appeared normal. Glenwright and Rock ${ }^{[96]}$ treated a case with penicillin, tetracycline and metronidazole at different times over eight years with unsuccessful outcome. Eronat et al ${ }^{[76]}$ prescribed amoxicillin-clavulanic acid every six months. No tooth loss was observed after 
more than two years follow-up period. De Vree et al. ${ }^{[77]}$ followed two PLS siblings for 15 years received intensive periodontal treatment along with metronidazole $(250 \mathrm{mg} /$ q.i.d for five days during periods of exacerbations). Treatment was successful in maintaining a number of permanent teeth in one patient but not in the other sibling. Yacoub and Hattab ${ }^{[25]}$ placed a patient on amoxicillin and metronidazole therapy taking concurrently (250 mg/t.i.d for seven days) every two to three months combined with mechanical and chemical periodontal methods. Only short-term improvement has been noticed. Based on follow-up microbiological testing, Pacheco et al ${ }^{[97]}$ applied amoxicillin/metronidazole therapy ( $250 \mathrm{mg}$ of each/3 time's daily/10 days) and repeated it after 4 months. At 16 months, the periodontium appeared normal.

The discrepancy in the outcome of PLS periodontitis therapy between studies could be related to the complex subgingival microbial communities and varieties in the etiopathogenesis factors. In addition, most studies were conducted on one or two patients who vary in severity of the condition, age, timing, duration and frequency of periodontal and antibiotic therapy, follow-up evaluation period, and patient compliance with the treatment protocol and home care.

\section{Oral treatment protocol}

Primary dentition

(1) Oral hygiene instruction and home care; (2) antibacterial/antiplaque agents. Chlorhexidine digluconate was recommended because of its broad antimicrobial effect and prolonged substantively (oral retention). It is available in forms of mouthrinse containing $0.2 \%\left(\right.$ Corsodyl $\left.^{\circ}\right)$ or $0.12 \%\left(\right.$ Peridex $\left.^{\oplus}\right)$, gel $1 \%$, and toothpaste. Children younger than the age of six should not use mouthwash because they may swallow large amounts of the liquid inadvertently. Instead, chlorhexidine gel can use on a toothbrush or in custom-made applicator trays; and (3) extraction of hopeless teeth eliminates periodontal pathogens and improves future prognosis of the permanent teeth. Extractions of teeth must perform under antibiotic cover to prevent.

\section{Permanent dentition}

(1) Oral hygiene instructions include continuous monitoring and frequent recalling appointments; (2) chlorhexidine gel or mouthrinse twice daily; (3) prophylaxis, such as scaling and root planing should be performed every 2-3 months; (4) extractions of mobile teeth or teeth during exacerbation of periodontal condition. This should be carried out under antibiotic cover (amoxicillin-metronidazole taken concurrently: $250 \mathrm{mg}$ of each/t.i.d daily/10 days); (5) splinting moderately mobile teeth; (6) restoring masticatory function by inserting partial or complete dentures; and (7) other treatment and rehabilitation options are dental implants ${ }^{[98,99]}$, calvarium bone grafts and dental implants ${ }^{[100]}$.

\section{Dermatological treatment}

The therapeutic goal for skin lesions is to remove sufficient callus to preserve function and to relieve pain over pressure points from fissures and cracks. Treatments based on topical application of lubricants, keratolytic agents contained 5\%-10\% salicylic acid, 10\% lactic acid, or 10\% urea in a neutral base (e.g., Keralyt gel). Topical anti-inflammatory steroids like betamethasone and systemic antibiotics where there is an inflammatory component. Dermabrasion may help topical agents penetrate keratoderma lesions. Gentian violet, Castellani's paint, or flexible collodions have been used to seal painful fissures. The use of antiperspirants and deodorants may help with excessive perspiration (hyperhidrosis) ${ }^{[6,101]}$. Retinoids are a group of substances comprising vitamin $\mathrm{A}$ and its natural and synthetic derivatives ${ }^{[02]}$. They were first used in dermatology in 1943 for acne vulgaris. Since 1971, topical retinoids have been extensively used for treatment of various skin conditions including acne, psoriasis, photoaging, and actinic keratosis. Retinoids exert therapeutic benefits in skin cellular division and differentiation, cell surface alterations, immune defense, and wound healing ${ }^{[101-103]}$. When topically applied, deficiency in collagen that exists in the skin is partially improved. Topical retinoids are available in cream, gel, and liquid forms. They work synergitistically with topical antibiotics. Tretinoin $(0.05 \%$ gel and $0.1 \%$ cream) was used to promote peeling of affected skin 
areas, but treatment can cause irritation of the surrounding skin. Oral retinoids were proven effective in the treatment of various types of keratinizing disorders, especially in some hereditary PPKs such as PLS, but long-term treatment is required. Treatment usually started at the time of eruption of permanent teeth. Etretinate, a retinoic acid analogue, is available in the form of Tigason (Tegison in US) is available 10 or 25 mg capsules. Acitretin a second-generation retinoid 10 or $25 \mathrm{mg}$ capsules. A typical starting dose is around 25-50 mg once per day or 0.5-1 mg/kg/day given in a single daily dose. Treatment usually continued for at least 6-8 weeks. Early identification of PLS is essential for potentially effective treatment with retinoid.

\section{DISCUSSION}

PLS is very rare disorder inherited in autosomal recessive pattern; that is, both parents are phenotypically healthy and there is no family history of the disease, other than the affected person. The two cardinal features of PLS are PPK and severe early onset of destructive periodontitis leading to premature loss of both primary and permanent dentitions. The etiopathogenesis of PLS is multifactorial with genetic, immunological, and microbial factors playing primary role. The genetic predisposition with greater occurrence in certain ethnic groups suggest that earlier statement of "no racial predominance of the condition ${ }^{\text {"5] }}$ is at present not universally applicable. The presence of variables in the onset, progression, and clinical expressions associated with the same CTSC gene mutation may reflect the influence of environmental and host factors in PLS etiopathogenicity. Immunological factors include the defect of immune-mediated mechanisms that reduced lymphocyte response to pathogens, decreased helper/suppressor T-cell ratio, impaired neutrophil and monocytes function, elevated serum immunoglobulin $G$ level, and degenerative changes in plasma cell $^{[55-57]}$. Bacteriological factors revealed that the presence of virulent anaerobic pathogens and their toxins in periodontal plaque and pockets play a major role in the pathogenesis and progression of rapid periodontal breakdown. Among the bacterial species recognized of being associated with severe periodontitis was A.a.

Diagnosis of PLS can be obtained by a thorough clinical examination of familial, medical and dental histories. Genetic testing was used to confirm the diagnosis of this syndrome. A diagnosis can be achieved by urine analysis of an infant or child to test the activity of the enzyme CTSC ${ }^{[94]}$. Early diagnosis and prompt treatment can potentially prevent aggressive periodontitis and tooth loss. Efforts should be directed to eliminate the reservoir of periodontal pathogens and to create safe environment for eruption of permanent teeth. Several treatment modalities are used to restore functional, esthetical and psychological impacts in order to improve overall quality of life on the growing children. This requires cooperation from dermatologists, pediatrician, periodontists, and prosthodontists.

\section{CONCLUSION}

PLS is very rare disorder inherited in autosomal recessive pattern. Even though, the condition is associated with lifelong functional; aesthetical; psychological; and social impacts on the growing children. The two cardinal features of PLS are PPK and severe early onset of destructive periodontitis leading to premature loss of both primary and permanent dentitions. The etiopathogenesis of the disorder is multifactorial with genetic, immunological, and microbial factors playing a major role. A genetic predisposition with greater frequency of occurrence in consanguineous offspring is evident. Other significant causative factors are environmental and reduced host defense mechanism. Virulent pathogens and their toxins in the subgingival plaque play a major factor in the initiation and progression of PLS periodontitis. Diagnosis of PLS can be obtained by a thorough clinical examination, familial, medical and dental histories. Genetic testing confirms the diagnosis of the syndrome. Awareness and early diagnosis of the syndrome is essential, to provide appropriate and comprehensive dental and medical care. Management of the disorder directed toward halting periodontal destruction by eliminating the reservoir of causative organisms; using conventional periodontal treatment, oral hygiene instructions, antiseptic mouth rinses; and systemic antibiotic. Coordinated team of specialists is critical for the overall care of patients suffering from PLS. 


\section{DECLARATIONS}

\section{Authors' contributions}

The author contributed solely to the article.

\section{Availability of data and materials}

Not applicable.

\section{Financial support and sponsorship}

None.

\section{Conflicts of interest}

There are no conflicts of interest.

\section{Ethical approval and consent to participate}

Not applicable.

\section{Consent for publication}

Not applicable.

\section{Copyright}

(C) The Author(s) 2019.

\section{REFERENCES}

1. Papillon MM, Lefevre P. Deux cas de keratoderma palmaire et plantaire symmetrique familiale (maladie de Meleda) chez le frere et la soeur: coexistence dans les deux cas d'alterations dentaires graves. Bull Soc Fr Dermatol Syph 1924;31:82-7.

2. Gorlin RJ, Sedano H, Anderson VE. The syndrome of palmar-plantar hyperkeratosis and premature periodontal destruction of the teeth. J Pediatr 1964;65:895-908.

3. Haneke E. The Papillon-Lefèvre syndrome: keratosis palmoplantaris with periodontopathy. Report of a case and review of the cases in the literature. Hum Genet 1979;51:1-35.

4. Hattab FN, Rawashdeh MA, Yassin OM, al-Momani AS, al-Ubosi MM.Papillon-Lefèvre syndrome: a review of the literature and report of 4 cases. J Periodontol 1995;66:413-20.

5. Hart TC, Shapira L. Papillon-Lefèvre syndrome. Periodontol 20001994;6:88-100.

6. Hattab FN, Amin WM. Papillon-Lefèvre syndrome with albinism: a review of the literature and report of 2 brothers. Oral Surg Oral Med Oral Pathol Oral Radiol Endod 2005;100:709-16.

7. AIBarrak ZM, Alqarni AS, Chalisserry EP, Anil S. Papillon-Lefèvre syndrome: a series of five cases among siblings. J Med Case Rep 2016;22;10:260.

8. Teebi AS. Genetic disorders among Arab populations. Heidelberg: Springer-Verlag Berlin; 2010.

9. Rathod VJ, Joshi NV. Papillon-Lefevre syndrome: a report of two cases. J Indian Soc Periodontol 2010;14:275-8.

10. Khan FY, Jan SM, Mushtaq M. Papillon-Lefèvre syndrome: case report and review of the literature. JIndian Soc Periodontol 2012;16:261-5.

11. Kaur B. Papillon Lefevre syndrome: a case report with review. Dentistry 2013;3:156.

12. Sreeramulu B, Shyam ND, Ajay P, Suman P. Papillon-Lefèvre syndrome: clinical presentation and management options. Clin Cosmet Investig Dent 2015;7:75-81.

13. Bhavsar MV, Brahmbhatt NA, Sahayata VN, Bhavsar NV. Papillon-lefevre syndrome: case series and review of literature. J Indian Soc Periodontol 2013;17:806-11.

14. Hacham-Zadeh S, Schaap T, Cohen MM. A genetic analysis of the Papillon-Lefèvre syndrome in a Jewish family from Cochin. Am J Med Genet 1978;2:153-7.

15. Kansky AA, Potocnik M, Kansky A. Papillon-Lefèvre syndrome. Acta Dermatovenerologica 1997;6:60-5.

16. Modell B, Darr A. Science and society: genetic counselling and customary consanguineous marriage. Nat Rev Genet 2002;3:225-9.

17. Hamamy H. Consanguineous marriages: preconception consultation in primary health care settings. J Community Genet 2012;3:185-92.

18. Khoury SA, Massad DD. Consanguineous marriage in Jordan. Am J Med Genet 1992;43:769-75.

19. el-Hazmi MA, al-Swailem AR, Warsy AS, al-Swailem AM, et al. Consanguinity among the Saudi Arabian population.J Med Genet 1995;32:623-6.

20. Shawky RM, Elsayed SM, Zaki ME, El-Din SMN, et al. Consanguinity and its relevance to clinical genetics. Egyp J Med Hum Genet 2013;14:157-64.

21. Bhagya B, Sucharitha S, Avadhani R. Prevalence and pattern of consanguineous marriages among different communities in Mangalore. 
Online J Health Allied Sci 2012;11:7.

22. Baghdady VS. Papillon-Lefevre syndrome: report of four cases. ASDC J Dent Child 1982;49:147-50.

23. Pareek SS, Al-Aska AK. Papillon-Lefevre syndrome: a report of six cases in one family. Int J Dermatol 1986;25:638-41.

24. El Darouti MA, Al Raubaie SM, Eiada MA. Papillon-Lefèvre syn-drome. Successful treatment with oral retinoids in three patients. Int J Dermatol 1988;27:63-6.

25. Yacoub AA, Hattab FN. Oral and dermatologic findings in two siblings with Papillon-Lefevre syndrome: review of the literature. Qatar Med J 2008;17:63-7.

26. Soyele OO, Taiwo AO. Papillon-Lefèvre syndrome: clinical presentation and literature review. J Orofac Sci 2015;7:54-8.

27. Upadhyaya JD, Pfundheller D, Islam MN, Bhattacharyya I. Papillon-Lefèvre syndrome: a series of three cases in the same family and a literature review. Quintessence Int 2017;48:695-700.

28. Ghaffer KA, Zahran FM, Fahmy HM, Brown RS. Papillon-Lefèvre syndrome: neutrophil function in 15 cases from 4 families in Egypt. J Oral Surg Oral Med Oral Pathol Oral RadioEndod 1999;88:320-5.

29. Valeshabad AK, Mazidi A, Valeshabad RK, Imani E, Kord H, et al. Papillon-Lefèvre syndrome: a series of six cases in the same family. ISRN Dermatol 2012;2012:139104.

30. Keskin-Yildirim Z, Simşek-Derelioğlu S, Kantarci M, Yilmaz Y, Büyükavci M. Papillon-Lefèvre syndrome: report of three cases in the same family. Turk J Pediatr 2012;54:171-6.

31. Nagaveni NB, Suma R, Shashikiran ND, Reddy SVV. Papillon-Lefevre syndrome: report of two cases in the same family. J Indian Soc Pedod Prev Dent 2008;26:78-81.

32. Laass MW, Hennies HC, Preis S, Stevens HP, Jung M, et al. Localization of a gene for Papillon-Lefèvre syndrome to chromosome Ilq14-q21 by homozygosity mapping. Hum Genet 1997;101:376-82.

33. Toomes C, James J, Wood AJ, Wu CL, McCormick D, et al. Loss-of-function mutations in the cathepsin C gene results in periodontal disease and palmoplantar keratosis. Nat Genet 1999;23:421-4.

34. Hart TC, Hart PS, Bowden DW, Michalec MD, Callison SA, et al. Mutations of the cathepsin C gene are responsible for Papillon-Lefevre syndrome. J Med Genet 1999;36:881-7.

35. McGuire MJ, Lipsky PE, Thiele DL. Purification and characterization of dipeptidyl peptidase I from human spleen. Arch Biochem Biophys 1992;295:280-8.

36. Rao NV, Rao GV, Hoidal JR. Human dipeptidyl-peptidaseI. Gene characterization, localization and expression. J Biol Chem 1997;272:10260-5.

37. Hewitt C, McCormick D, Linden G, Turk D, Stern I, et al. The role of cathepsin C in the Papillon-Lefèvre syndrome, prepubertal periodontitis, and aggressive periodontitis. Hum Mutat 2004;23:222-8.

38. Hart TC, Hart PS, Michalec MD, Zhang Y, Firatli E, et al. Haim-Munk syndrome and Papillon-Lefèvre syndrome are allelic mutations in cathepsin C. J Med Genet 2000;37:88-94.

39. Hart PS, Zhang Y, Firatli E, Uygur C, Lotfazar M, et al. Identification of cathepsin C mutations in ethnically diverse Papillon-Lefèvre syndrome patients. J Med Genet 2000;37:927-32.

40. Lefèvre C, Blanchet-Bardon C, Jobard F, Bouadjar B, Stalder JF, et al. Novel point mutations, deletions, and polymorphisms in the cathepsin C gene in nine families from Europe and North Africa with Papillon-Lefèvre syndrome. J Invest Dermatol 2001;117:1657-61.

41. Noack B, Görgens H, Hoffmann T, Fanghänel J, Kocher T, et al. Novel mutations in the cathepsin C gene in patients with pre-pubertal aggressive periodontitis and Papillon-Lefèvre syndrome. J Dent Res 2004;83:368-70.

42. Nagy N, Vályi P, Csoma Z, Sulák A, Tripolszki K, et al. CTSC and Papillon-Lefèvre syndrome: detection of recurrentmutations in Hungarian patients, a review of published variants and database update. Mol Genet Genomic Med 2014;2:217-28.

43. Hewitt C, Wu CL, Hattab FN, Amin W, Ghaffar KA, et al. Coinheritance of two rare genodermatoses (Papillon- Lefèvre syndrome and oculocutaneous albinism type 1) in two families: a genetic study. Br J Dermatol 2004;151:1261-5.

44. Pharm CT. Neutrophil serine proteases: specific regulators of inflammation. Nat Rev Immunol 2006;6:541-50.

45. Roberts H, White P, Dias I, McKaig S, Veeramachaneni R, et al. Characterization of neutrophil function in Papillon- Lefèvre syndrome. J Leukoc Biol 2016;100:433-44.

46. Van Dyke TE, Taubman MA, Ebersole JL, Haffajee AD, Socransky SS, et al. The Papillon-Lefévre syndrome: neutrophildysfunction with severe periodontal disease. Clin Immunol Immunopathol 1984;31:419-29.

47. Preus H, Gjermo P. Clinical management of prepubertal periodontitis in 2 siblings with Papillon-Lefévre syndrome. J Clin Periodontol $1987 ; 14: 156-60$.

48. Tinanoff N, Tempro P, Maderazo EG. Dental treatment of Papillon-Lefèvre syndrome: 15-year follow-up. J Clin Periodontol 1995;22:609-12.

49. Velazco CH, Coelho C, Salazar F, Contreras A, Slots J, et al. Microbiological features of Papillon-Lefèvre syndrome periodontitis. J Clin Periodontol 1999;26:622-7.

50. Firatli E, Tüzün B, Efeoğlu A. Papillon-Lefèvre syndrome. Analysis of neutrophil chemotaxis. J Periodontol 1996;67:617-20.

51. Singh AP, Chaitra TR, Singh SP, Kulkarni AU. Initial expression of the Papillon-Lefèvre syndrome in consanguine family.BMJ Case Rep 2012; doi: 10.1136/bcr-2012-006313.

52. Page RC, Offenbacher S, Schroeder HE, Seymour GJ, Kornman KS. Advances in the pathogenesis of periodontitis: summary of development, clinical implications and future directions. Periodontol 2000 1997;14:216-48.

53. Levo Y, Wollner S, Hacham-Zadeh S. Immunological study of patients with the Papillon-Lefevre syndrome. Clin Exp Immunol 1980;40:407-10.

54. Borroni G, Pagani A, Carcaterra A, Pericoli R, Gabba P, et al. Immunological alterations in a case of Papillon-Lefèvre syndrome with recurrent cutaneous infections. Dermatologica 1985;170:27-30.

55. Celenligil H, Kansu E, Ruacan S, Eratalay K. Papillon-Lefèvre syndrome. Characterization of peripheral blood and gingival lymphocytes 
with monoclonal antibodies. J Clin Periodontol 1992;19:392-7.

56. Lundgren T, Parhar RS, Renvert S, Tatakis DN. Impaired cytotoxicity in Papillon-Lefèvre syndrome. J DentRes 2005;84:414-7.

57. Ham H, Billadeau DD. Human immunodeficiency syndromes affecting human natural killer cell cytolytic activity. Front Immunol 2014;5:2.

58. Bimstein E, Lustmann J, Sela MN, Neriah ZB, Soskolne WA. Periodontitis associated with Papillon-Lefévre syndrome. J Periodontol 1990;61:373-7.

59. Bullon P, Pascual A, Fernandez-Novoa MC, Borobio MV, Muniain MA, et al. Late onset Papillon-Lefèvre syndrome? A chromosomic, neutrophil function and microbiological study. J Clin Periodontol 1993;20:662-7.

60. Lundgren T. Papillon-Lefèvre syndrome: associations to clinical and laboratory factors and results of treatment. Available from: http:// muep.mau.se/handle/2043/7931. [Last accessed on 25 Dec 2018]

61. Ishikawa I, Umeda M, Laosrisin N. Clinical, bacteriological, and immunological examinations and the treatment process of two PapillonLefèvre syndrome patients. J Periodontal 1994;65:364-71.

62. Clerehugh V, Drucker DB, Seymour GJ, Bird PS. Microbiological and serological investigations of oral lesions in Papillon-Lefévre syndrome. J Clin Pathol 1996;49:255-7.

63. Wara-aswapati N, Lertsirivorakul J, Nagasawa T, Kawashima Y, Ishikawa I. Papillon-Lefèvre syndrome: serumimmunoglobulins G (IgG) subclass antibody response to periodontopathic bacteria. A case report. J Periodontol 2001;72:1747-54.

64. Vrahopoulos TP, Barber P, Liakoni H, Newman HN. Ultrastructure of the periodontal lesion in a case of Papillon-Lefèvre syndrome (PLS). J Clin Periodontol 1988;15:17-26.

65. Cheung HS, Landow RK, Bauer M. Increased collagen synthesis by gingival fibroblasts derived from a Papillon-Lefèvre patient. J Dent Res 1982;61:378-81.

66. Landow RK, Cheung H, Bauer M. Papillon-Lefèvre syndrome. Int J Dermatol 1983;22:177-9.

67. Sloan P, Soames JV, Murray JJ, Jenkins WM. Histopathological and ultrastructural findings in a case of Papillon-Lefèvre syndrome. J Periodontol 1984;55:482-5.

68. Kleinfelder JW, Topoll HH, Preus HR, Müller RF, Lange DE, et al. Microbiological and immunohistological findings in a patient with Papillon-Lefèvre syndrome. J Clin Periodontol 1996;23:1032-8.

69. Proceedings of the 1996 World Workshop in periodontics. Lansdowne, Virginia, July 13-17, 1996. Ann Periodontol 1996;1:1-947.

70. Socransky SS, Haffajee AD, Cugini MA, Smith C, Kent RL Jr. Microbial complexes in subgingival plaque. J Clin Microbiol 1998;25:134-44.

71. Popova C, Dosseva-Panova V, Panov V. Microbiology of periodontal diseases. A review. Biotechnol \& Biotechnol Eq 2013;27:3754-9.

72. Newman M, Angel I, Karge H, Weiner M, Grinenko V, et al. Bacterial studies of Papillon-Lefévre syndrome. J Dent Res 1977;56:545.

73. Robertson KL, Drucker DB, James J, Blinkhorn AS, Hamlet S, et al. A microbiological study of Papillon-Lefèvre syndrome in two patients. J Clin Pathol 2001;54:371-6.

74. Albandar JM, Khattab R, Monem F, Barbuto SM, Paster BJ. The subgingival microbiota of Papillon-Lefèvre syndrome. J Periodontol 2012;83:902-8.

75. Slots J. Human viruses in periodontitis. Periodontol 2000 2010;53:89-110.

76. Eronat N, Ucar F, Kilinc G. Papillon-Lefevre syndrome: treatment of two cases with a clinical microbiological and histopathological investigation. J Clin Pediatr Dent 1993;17:99-104.

77. De Vree H, Steenackers K, De Boever JA. Periodontal treatment of rapid progressive periodontitis in 2 siblings with Papillon-Lefèvre syndrome: 15-year follow-up. J Clin Periodontol 2000;27:354-60.

78. Ullbro C, Twetman S.Review paper: dental treatment for patients with Papillon-Lefèvre syndrome (PLS). Eur Arch Paediatr Dent 2007;8:4-11.

79. Nuckolls GH, Slavkin HC. Paths of glorious proteases. Nat Genet 1999;23:378-80.

80. Almuneef M, Al Khenaizan S, Al Ajaji S, Al-Anazi A. Pyogenic liver abscess and Papillon-Lefèvre syndrome: not a rare association. Pediatrics 2003;111:e85-8.

81. Yazdanfar A, Farahnaki S. Late onset Papillon-Lefevre syndrome with pyogenic liver abscesses: report of one case. Int J Dermatol 2009;48:76-8.

82. Brown RS, Hays GL, Flaitz CM, O’Neill PA, Abramovitch K, et al. A possible late onset variation of Papillon-Lefèvre syndrome: report of 3 cases. J Periodontol 1993;64:379-86.

83. Soskolne WA, Stabholz A, van Dyke TE, Hart TC, Meyle J. Partial expression of the Papillon-Lefèvre syndrome in 2 unrelated families. J Clin Periodontol 1996;23:764-9.

84. Fardal O, Drangsholt E, Olsen I. Palmar plantar keratosis and unusual periodontal findings. Observations from a family of 4 members. J Clin Periodontol 1998;25:181-4.

85. Pilger U, Hennies HC, Truschnegg A, Aberer E. Late-onset Papillon-Lefèvre syndrome without alteration of the cathepsin C gene. J Am Acad Dermatol 2003;49:S240-3.

86. Matthews JB, Wright HJ, Roberts A, Ling-Mountford N, Cooper PR, et al. Neutrophil hyper-responsiveness in periodontitis. J Dent Res 2007;86:718-22.

87. Palmer LJ, Cooper PR, Ling MR, Wright HJ, Huissoon A, et al. Hypochlorous acid regulates neutrophil extracellular trap release in humans. Clin Exp Immunol2012;167:261-8.

88. Thakare KS, Bhongade ML, Charde P, Kale S, Jaiswal P, et al. Genetic mapping in Papillon-Lefèvre syndrome: a report of two cases. Case Rep Dent2013;2013:404120.

89. Sørensen OE, Clemmensen SN, Dahl SL, Østergaard O, Heegaard NH, et al. Papillon-Lefèvre syndrome patient reveals species-dependent requirements for neutrophil defenses. J Clin Invest 2014;124:4539-48.

90. Sachdeva S, Kalra N, Kapoor P. Papillon-Lefèvre syndrome: report of a case and its management. J Clin Exp Dent 2012;4:e77-81.

91. Ullbro C, Crossner CG, Nederfors T, Alfadley A, Thestrup-Pedersen K. Dermatological and oral findings in a cohort of 47 patients with 
Papillon-Lefèvre syndrome. J Am Acad Dermatol 2003;48:345-51.

92. Firatli E, Gürel N, Efeoglu A, Badur S. Clinical and immunological findings in 2 siblings with Papillon-Lefèvre syndrome. J Periodontol 1996;67:1210-5.

93. Dababneh RH, Jebrin SE, Khouri AT, Bissada NF. Papillon-Lefèvre or Haim-Munk syndrome? Report on two sisters in a consanguineous family. Clin Adv Periodont 2015;5:192-200.

94. Hamon Y, Legowska M, Fergelot P, Dallet-Choisy S, Newell L, et al. Analysis of urinary cathepsin C for diagnosing Papillon-Lefèvre syndrome. FEBS J 2016;283:498-509.

95. Dababneh RH, Bissada NF. Syndromes that include both palmoplantar keratoderma and severe periodontitis: a review. Dentistry 2013;4:186.

96. Glenwright HD, Rock WP. Papillon-Lefevre syndrome: a discussion of aetiology and a case report. Br Dent J 1990;168:27-9.

97. Pacheco JJ, Coelho C, Salazar F, Contreras A, Slots J, et al. Treatment of Papillon-Lefèvre syndrome periodontitis. J Clin Periodontol 2002;29:370-4.

98. Ullbro C, Crossner CG, Lundgren T, Stålblad PA. Osseointegrated implants in a patient with Papillon-Lefevre syndrome: a 41/2-year follow up. J Clin Periodontol 2000;27:951-4.

99. Senel FC, Altintas NY, Bagis B, Cankaya M, Pampu AA, et al. A 3-year follow-up of the rehabilitation of Papillon-Lefèvre syndrome by dental implants. J Oral Maxillofac Surg 2012;70:163-7.

100. Kinaia BM, Hope K, Zuhaili A, Tulasne JF. Full-mouth rehabilitation with calvarium bone grafts and dental implants for a Papillon-Lefèvre syndrome patient: case report. Int J Oral Maxillofac Implant 2017;32:e259-64.

101. National Organization for Rare Disorders (NORD). Papillon-Lefèvre syndrome. Available from: https://rarediseases.org/rare-diseases/ papillon-lefevre-syndrome/. [Last accessed on 25 Dec 2018]

102. Riahi RR, Bush AE, Cohen PR. Topical retinoids: therapeutic mechanisms in the treatment of photodamaged skin. Am J Clin Dermatol 2016;17:265-76.

103. Sarkar R, Chugh S, Garg VK. Acitretin in dermatology. Indian J Dermatol Venereol Leprol 2013;79:759-71. 